Copyright (C) 2021 The Author/s

This work is licensed under a CC-BY 3.0 License

Peer review method: Double-Blind

Accepted: August 16, 2021

Published: September 21, 2021

Original scientific article

DOI: https://doi.org/10.47305/JLIA2137033b

\title{
\#METOO AND US POLITICS: ANALYSING THE TWITTER CONVERSATION
}

\author{
Vittoria Bernardini \\ Sapienza University of Rome, Italy \\ ORCID iD: https://orcid.org/0000-0002-7976-1368 \\ vittoria.bernardini@uniroma1.it
}

\begin{abstract}
The \#MeToo movement has had a profound cultural impact on US society, and notably on US party politics. While many studies have addressed the \#MeToo-related controversy arising from the Brett Kavanaugh nomination to Supreme Court Justice in 2018, the relationship between \#MeToo and US politics before this event has remained understudied. This article, therefore, addresses this gap by looking at the role of politics at the beginning of the \#MeToo movement. Focusing on the first six months of online activity on Twitter (October 2017 - April 2018), over 2 million tweets with the \#MeToo hashtag are analyzed to identify the main activity patterns across the dataset and to gain insight on user behavior and participation in the conversation. Results point to the weaponization of \#MeToo in the political context from its inception. It is suggested that \#MeToo reflects the polarized political climate in the US and that it can be conceptualized as part of the wider "culture wars" (Hunter 1991) that characterize the public debate.
\end{abstract}

Keywords: \#MeToo; US Politics; Political Polarization; Donald Trump; Twitter

\section{INTRODUCTION}

\#MeToo emerged in 2017 as a movement to combat sexual violence, and the hashtag quickly gained immense popularity on social media. Participation in the hashtag campaign has been described as "nothing short of phenomenal" and turned \#MeToo into a "moment of reckoning" for sexual violence (Fileborn and Loney-Howes 2019, 3). The movement became internationally prominent, as numerous versions of the hashtag were developed for different national contexts and languages. Despite its global popularity, however, data seems to show that the movement remained dominated by US personalities and themes. For example, studies have indicated that peaks in social media activity and the news corresponded to events related to American personalities from show business or politics (Anderson and Toor 2018; De Benedictis et al. 2019). Additionally, in the same period, $71 \%$ of all tweets were written in English (Anderson and Toor 2018). Given the relevance of US culture to the movement, then, one aspect that 
has remained understudied is the relationship between \#MeToo and US politics. The \#MeToo conversation that began in 2017 proved immediately influential on US politics, as $44 \%$ of members of Congress addressed the issue of sexual misconduct in their Facebook posts between October and December 2017 (Lam et al. 2018). The centrality of \#MeToo in US politics became undeniable in 2018 when President Trump nominated Judge Brett Kavanaugh for the position of Associate Justice of the Supreme Court of the United States. Following the nomination, psychology professor Dr. Christine Blasey-Ford publicly accused Kavanaugh of sexually assaulting her at a party when they were in high school, leading to a heated debate in the public sphere. This \#MeToo-related controversy is perhaps the most revealing example of a central tension in US politics. On the one hand, the popularity of the \#MeToo movement is part of a wider revival of feminist politics and anti-sexual violence activism. On the other hand, it has also been suggested that the election of Trump and Kavanaugh's confirmation are "indicative of a backlash against women's rights - a statement against identity politics and so-called political correctness - and that for all the attention \#MeToo received, a counterattack was simultaneously being mounted by conservatives" (Rosewarne 2019, 174).

The purpose of this article, then, is to investigate this tension by analyzing the relationship between the \#MeToo movement and US party politics. Most existing studies on \#MeToo have rather focused on aspects regarding its visibility in the media and the role of digital activism (e.g., Boyle 2019; Clark-Parsons 2019; De Benedictis et al. 2019; Fileborn and Loney-Howes 2019; Zacchia et al. 2019). Two notable exceptions (Boyle and Rathnayake 2019; Pollino 2020) have focused on the Kavanaugh case as the most salient political controversy related to \#MeToo. Building on the work of these authors, who show how \#MeToo was weaponized in the politically polarized climate in the US, this article looks at the role of politics at the beginning of the \#MeToo movement, focusing on the first six months of online activity on Twitter (October 2017 April 2018). Through the analysis of over 2 million tweets with the \#MeToo hashtag, this study aims to explore how the political weaponization of \#MeToo appeared in the public debate long before the Kavanaugh case emerged in summer 2018.

\section{\#METOO AND THE US POLITICAL CONTEXT}

The emergence of the \#MeToo movement has been linked by many authors to the wider context of the Trump presidency (Banet-Weiser 2018; Rosewarne 2019; Rottenberg 2019). After Trump's election in 2016, many protests took place in the US and across the globe against his campaign rhetoric and his actions while in office. Protesters opposed Trump's anti-progressive values on issues such as gender equality, reproductive rights, and immigration (Fisher, Dow, and Ray 2017). In 2016, the Washington Post published a leaked audiotape of Trump making "extremely lewd" comments about women (Fahrenthold 2016). 
The tape received "universal condemnation" from all political factions and represented the first time that "a presidential candidate's own words expressed such graphic, lewd, and abusive language about women" (Rhodes et al. 2020, 2). In response to the content of the tape, thousands of women began using the hashtag \#NotOkay to share narratives of sexual assault and to proclaim that Trump's comments should not be minimized (Maas et al. 2018).

The most notable protest took place offline when more than two million people participated in the Women's March on 21 January 2017 (the day after Trump's inauguration), one of the largest protests ever observed in the United States (Fisher, Dow, and Ray 2017). The main demonstration took place in Washington, DC, while hundreds of other events were organized across the United States and internationally.

This resurgence of feminist activism to contrast the election of a misogynist president reflects a tension between what Banet-Weiser (2018) has named "popular feminism" and "popular misogyny". The term "popular feminism" refers to a revival of feminist ideas and activism that is especially "tied to media visibility, circulation, and affective embrace" (Banet-Weiser et al. 2020, 4), particularly on social media platforms. In contrast, "popular misogyny" refers both to the "social, political, economic, and cultural structure" of patriarchal societies (Banet-Weiser 2018, 17) and to the more recent "reaction to the culture-wide circulation and embrace of feminism" (Banet-Weiser 2018 , 3). As Löffler, Luyt, and Starck $(2020,1)$ note, sexism, and misogyny are "newly emerging versions of right-wing populism: (...) they oppose feminism and genderequality measures, same-sex marriage, and gender studies; they seek to re-instantiate traditional family and associated gender roles, and they pursue a strong-man style of political leadership". The revitalization of populist and conservative politics across Western countries has contributed to invigorating sexist ideas and policies (Rottenberg 2019). In this sense, the revival of feminist protests since the 2010s can also be understood as a backlash against the newfound institutional legitimization of conservative views on gender. This is the context where the \#MeToo movement originated. The use of the hashtag \#MeToo first began in October 2017, following a story in the New York Times uncovering sexual assault allegations against Hollywood producer Harvey Weinstein (Kantor and Twohey 2017). Amid the controversy that ensued, actress Alyssa Milano tweeted:

Me Too.

Suggested by a friend: "If all the women who have been sexually harassed or assaulted wrote 'Me Too' as a status, we might give people a sense of the magnitude of the problem" (@AlyssaMilano, 15 October 2017).

The hashtag proved immensely popular; it is estimated that it was used over 85 million times across social media in the first 45 days, covering 85 countries around the world (Sayej 2017). By September 2018, almost one year after the initial tweet, \#MeToo 
had appeared in more than 19 million posts on Twitter, averaging 55,319 uses of the hashtag per day (Anderson and Toor 2018). This extremely high level of online activity, therefore, offers ample opportunity to research the topics discussed in the \#MeToo conversation, as detailed in the next section.

\section{METHODOLOGY}

This article examines the relevance of US politics in the first six months of the \#MeToo movement on Twitter. Twitter is chosen as the research site because it is widely used in the public arena. Given that the majority of posts and interactions are publicly accessible, users often focus on issues that are also public and political (Papacharissi and de Fatima Oliveira 2012). By conceiving of Twitter as a digital public sphere, then, the platform offers the best space to understand the political aspects of the \#MeToo conversation. The dataset for the study was provided by the 'Minerva' project, cofinanced by the Foundation for European Progressive Studies and the Economia Civile association (see Zacchia et al. 2019). The dataset contains 2,015,900 public Twitter posts generated between October 2017 and April 2018 containing the \#MeToo hashtag and other local versions of the hashtag. ${ }^{1}$ The vast majority of tweets are in English (78.6\%); other significant languages include French (5.4\%), German (2.5\%), and Spanish (2\%). The data and metadata available for all tweets were analyzed to identify the main communicative patterns in the six months of the \#MeToo conversation. Using SPSS and Excel as the principal software for quantitative analysis, the entire dataset was analyzed to obtain key metrics on the following dimensions: user activity, retweets, and hashtags. The overall objective is to identify the main activity patterns across the dataset and to gain insight into user behavior and participation in the conversation (Bruns and Stieglitz 2012; Bruns 2018).

\section{RESULTS}

The first dimension analyzed is user activity. The total number of unique users in the dataset is 830,942 . This means that each user produced on average 2.42 tweets, with the top 10 most active users authoring around $1.4 \%$ of all tweets in the dataset. User mentions constitute an especially useful and metric to better understand the roles different users assume in the dataset: "Users who receive many @mentions, but rarely @reply in return must be seen mainly as subjects of conversation; users who both receive and send @replies frequently, by contrast, are active subjects within conversation" (Bruns and Stieglitz 2014, 73). 20.4\% of tweets in the dataset contain one

\footnotetext{
${ }^{1}$ 94\% of the posts contain the hashtag \#MeToo; the other hashtags are \#balancetonporc (France), \#120db (Germany), \#yotambien (Spain and Latin America), \#sistabriefen (Sweden) and \#quellavoltache (Italy).
} 
or more user mentions; $69 \%$ of tweets have only one mention while the remaining $31 \%$ include between 2 and 60 mentions. Table 1 compares the top 20 users who received the most mentions with the number of \#MeToo tweets they posted, to understand the ratio of 'subjects of conversation' vs. active participation.

Table 1: Top 20 Most Mentioned Users vs. the Number of \#MeToo Tweets They Posted ${ }^{2}$ (Source: Authors' depiction)

\begin{tabular}{|l|l|c|c|c|}
\hline \multicolumn{1}{|c|}{ User } & \% of Total Mentions & $\begin{array}{c}\text { \#MeToo } \\
\text { Posts }\end{array}$ & Type of User \\
\hline $\mathbf{1}$ & youtube & 3.9 & 0 & Digital platform \\
\hline $\mathbf{2}$ & realdonaldtrump / potus ${ }^{3}$ & 3.3 & 0 & Political actor \\
\hline $\mathbf{3}$ & time & 1.3 & 71 & News outlet \\
\hline $\mathbf{4}$ & oprah & 1.3 & 0 & Celebrity \\
\hline $\mathbf{5}$ & alyssa_milano & 1 & 134 & Celebrity \\
\hline $\mathbf{6}$ & taranaburke & 1 & 56 & Political actor \\
\hline $\mathbf{7}$ & tonyrobbins & 1 & 0 & Celebrity \\
\hline $\mathbf{8}$ & nytimes & 0.9 & 74 & News outlet \\
\hline $\mathbf{9}$ & alfranken / senfranken ${ }^{4}$ & 0.7 & 1 & Political actor \\
\hline 10 & rosemcgowan & 0.7 & 18 & Celebrity \\
\hline 11 & cnn & 0.6 & 82 & News outlet \\
\hline 12 & gop & 0.6 & 0 & Political organization \\
\hline 13 & hillaryclinton & 0.4 & 0 & Political actor \\
\hline 14 & sengillibrand & 0.4 & 9 & Political actor \\
\hline 15 & jimmykimmel & 0.3 & 0 & Celebrity \\
\hline 16 & thedailybeast & 0.3 & 153 & News outlet \\
\hline 17 & foxnews & 0.3 & 41 & News outlet \\
\hline 18 & womensmarch & 0.3 & 18 & Political organization \\
\hline 19 & asiaargento & 0.3 & & Celebrity \\
\hline 20 & kesharose & 0.3 & Celebrity \\
\hline & & & & \\
\hline
\end{tabular}

\footnotetext{
${ }^{2}$ Indication based only on the first mention in the tweet, not all mentions in all tweets. The variable mention 1 includes 411,701 users. Given that two individuals in the top 20 mentions have two accounts (Donald Trump's @realdonaldtrump and @potus; Al Franken's @alfranken and @senfranken), data for the respective accounts are added up and counted as one.

3 @realdonaldtrump is mentioned 11,292 times (2.7\%) and @potus 2,458 times (0.6\%).

4 @alfranken is mentioned 1,519 times (0.4\%) and @senfranken 1,406 (0.3\%). The \#MeToo tweet was posted by @senfranken.
} 
The data in Table 1 reveal some interesting insights into the users who are at the center of the conversation, showing a combination of Hollywood individuals, media outlets reporting on \#MeToo, and political figures. Except for actress Asia Argento, all users are US-based individuals or organizations. The first most mentioned account is @YouTube; this is simply because, when sharing a video from Youtube to Twitter, the mention is automatically included in the tweet.

Several US politicians appear prominently, with President Trump being the most discussed individual in the conversation. Another political controversy emerges with the presence of Al Franken, a Minnesota Senator who resigned after being accused of sexual misconduct, and Kirsten Gillibrand, the so-called "\#MeToo senator" (Siddiqui 2019) who was especially outspoken against Franken.

As expected, the role of mainstream media is also prominent. Time Magazine and the New York Times are the two most mentioned news outlets, given their significance in propelling and publicizing \#MeToo stories. The role of show business in inciting conversation is evident, as the list includes some of the actresses and television hosts who most vocally spoke out about \#MeToo.

It is also observable how, as Bruns and Stieglitz (2013) suggest, some actors are only part of the debate as topics of conversation but do not take on an active role. This is most evident in the case of Donald Trump, who is the individual most often mentioned in the whole dataset but who has never tweeted using \#MeToo or related hashtags. The centrality of well-known individuals and organizations in the \#MeToo conversation is also confirmed by looking at the 100 users who received the most mentions (Figure 1). The chart mostly reflects the same trends as the top 20 most mentioned users, with the addition of a slightly larger role for digital platforms (such as social networking sites, Netflix, and Amazon) and journalists and writers. Significantly, neither Twitter influencers nor 'common' users appear among the top mentions; while common users contributed to a vast majority of the tweets in the dataset, their influence was not sufficient to overshadow the fame of figures from entertainment, politics, and the media. This confirms the argument by Poell and Van Dijck $(2016,230)$ who underline how social media tend to follow a similar logic to traditional mass media in enhancing "the visibility of particular actors and topics". Metrics on mentions are especially revealing of the centrality of US politics in \#MeToo. Among the top 100 mentioned users, the highest share of mentions refers to the category of political actors or organizations (30\%, Figure 1), calling 25 unique users into the discussion. Among these, 8 are Republican politicians or groups, while 10 are Democrats. $^{5}$

\footnotetext{
${ }^{5}$ The remaining 7 are organizations or individuals that are not politically affiliated with either party.
} 


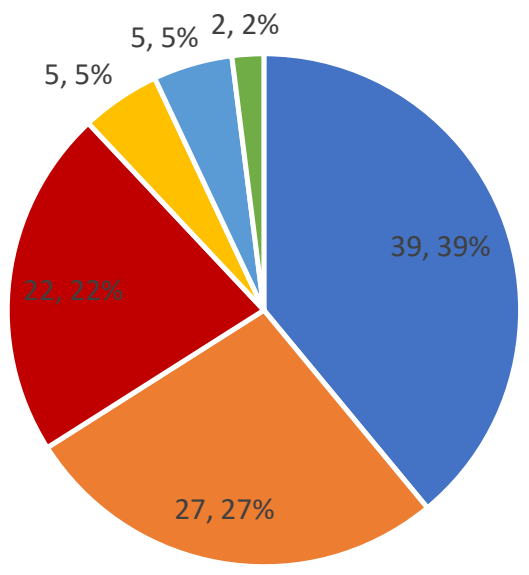

- News outlet

- Political actor

- Celebrity

- Digital platform

- News personality

- Commercial actor

Figure 1: Type of User for the 100 Most Mentioned Users (Source: Authors' depiction)

Retweets are the second dimension analyzed. They are a useful metric to understand the role of posts and users in the conversation. Bruns et al. (2016) consider retweeting as one of the key elements to analyze user engagement in hashtag publics.

Overall, in the dataset, $77.3 \%$ of tweets have 0 retweets and $20.2 \%$ of tweets have between 1 and 10 retweets. Only $0.3 \%$ of posts have more than 100 retweets and $0.03 \%$ have more than 1,000 retweets. Although these percentages are quite low, looking at retweets can still provide some further insights into the conversation. Table 2 shows the 20 posts with the highest number of retweets in the dataset. The range of users who authored the most popular posts appears quite varied in comparison with the top mentioned users (see Table 1). 
Table 2: Most Retweeted Tweets in the Dataset (Source: Authors' depiction)

\begin{tabular}{|c|c|c|c|c|}
\hline & User & Retweets & Type of User & Tweet \\
\hline 1 & apbenven & 55,406 & $\begin{array}{c}\text { News } \\
\text { personality }\end{array}$ & $\begin{array}{l}\text { A reminder that if a woman didn't post \#MeToo, it } \\
\text { doesn't mean she wasn't sexually assaulted or } \\
\text { harassed. Survivors don't owe you their story. }\end{array}$ \\
\hline 2 & funder & 46,371 & $\begin{array}{c}\text { News } \\
\text { personality }\end{array}$ & $\begin{array}{l}\text { The } 16 \text { women who accused Trump of sexual assault } \\
\text { are telling their story in one video-please share this far } \\
\text { and wide. RT if you agree it's time for Trump to be } \\
\text { held accountable for his sexual misconduct. } \\
\text { \#TrumpSexProbe \#AMJoy \#MeToo } \\
\text { pic.twitter.com/hNlqZEI54G }\end{array}$ \\
\hline 3 & funder & 39,128 & $\begin{array}{c}\text { News } \\
\text { personality }\end{array}$ & $\begin{array}{l}\text { @SpeakerRyan - Everyone who retweets this wants } \\
\text { you to open up an investigation into the } 20 \text { sexual } \\
\text { assault claims against Donald Trump. Quit being silent } \\
\text { on the issue. Is your "fight against sexual misconduct" } \\
\text { a complete fraud? It is if you don't probe Trump. } \\
\text { \#TrumpSexProbe \#MeToo }\end{array}$ \\
\hline 4 & womensmarch & 31,924 & $\begin{array}{c}\text { Political } \\
\text { organization }\end{array}$ & $\begin{array}{l}\text { To all the women sharing stories of sexual assault and } \\
\text { sexual harassment, thank you for your bravery to } \\
\text { speak up. You are not alone. \#MeToo }\end{array}$ \\
\hline 5 & McKaylaMaroney & 30,370 & Celebrity & \#MeToo pic.twitter.com/IYXaDTuOsS \\
\hline 6 & LeeannTweeden & 25,457 & Celebrity & $\begin{array}{l}\text { I've decided it's time to tell my story. \#MeToo, } \\
\text { http://www.kabc.com/2017/11/16/lee ann-tweeden- } \\
\text { on-senator-al-franken/ ... }\end{array}$ \\
\hline 7 & BetteMidler & 23,166 & Celebrity & $\begin{array}{l}\text { Tomorrow is my birthday. I feel like this video was a } \\
\text { gift from the universe to me. Geraldo may have } \\
\text { apologized for his tweets supporting Matt Lauer, but } \\
\text { he has yet to apologize for this. \#MeToo } \\
\text { pic.twitter.com/TkcolFWfA2 }\end{array}$ \\
\hline 8 & Simone_Biles & 23,010 & Celebrity & Feelings... \#MeToo pic.twitter.com/ICiuOFCa0n \\
\hline 9 & Pappiness & 21,281 & $\begin{array}{c}\text { News } \\
\text { personality }\end{array}$ & $\begin{array}{l}\text { Men, Don't say you have a mother, a sister, a } \\
\text { daughter... Say you have a father, a brother, a son who } \\
\text { can do better. We all can. \#MeToo }\end{array}$ \\
\hline 10 & celia_yac & 21,000 & Individual & $\begin{array}{l}\text { \#balancetonporc Un homme marchait derrière moi, } \\
\text { m'amit la main entre les jambes } 2 \text { fois et m'asorti } \\
\text { "çavousplait ?» j'aiportéplainte: } \\
\text { pic.twitter.com/JWpHK6DTps }\end{array}$ \\
\hline 11 & cnnbrk & 18,982 & News outlet & $\begin{array}{l}\text { When I raise my hand, I am aware of all the women } \\
\text { who are still in silence. - Actress Viola Davis references } \\
\text { the \#MeToo movement during the Women's March in } \\
\text { Los Angeles, http://cnn.it/2mUGcQb } \\
\text { pic.twitter.com/xPb5vvA4BL }\end{array}$ \\
\hline 12 & GraceStarling4 & 16,452 & Individual & $\begin{array}{l}\text { For those carrying their \#MeToo with them silently, } \\
\text { you are loved, cherished, and believed. You do not } \\
\text { owe your story to anyone. }\end{array}$ \\
\hline 13 & itsgabrielleu & 16,195 & Celebrity & $\begin{array}{l}\text { You know us. We are your family members. Your } \\
\text { friends. Your co-workers. Your neighbors. And yes, } \\
\text { even your heroes. We are everywhere. \#Metoo, http:// } \\
\text { twitter.com/SInow/status/9 } 206257774777144576 \text {... }\end{array}$ \\
\hline 14 & Alyssa_Milano & 15,462 & Celebrity & $\begin{array}{l}\text { At the very same time that we are asking Franken to } \\
\text { resign from the senate -- we are allowing an accused } \\
\text { child molester to run for senate. At the very same time }\end{array}$ \\
\hline
\end{tabular}




\begin{tabular}{|c|c|c|c|c|}
\hline & & & & $\begin{array}{l}\text { that Silence Breakers is the \#TimePersonOfTheYear -- } \\
\text { a self-professed pussy grabber was runner-up. } \\
\text { \#MeToo }\end{array}$ \\
\hline 15 & goldengateblond & 14,522 & $\begin{array}{l}\text { Twitter } \\
\text { influencer }\end{array}$ & $\begin{array}{l}\text { Here's @Oprah 's entire speech. Watch it. If you've } \\
\text { already seen it, watch it again. \#MeToo \#TimesUp } \\
\text { pic.twitter.com/cAcVJreRzf }\end{array}$ \\
\hline 16 & MarleeMatlin & 13,545 & Celebrity & $\begin{array}{l}\text { \#MeToo. I was } 14 \text {, he was } 36 . \text { I may be Deaf, but } \\
\text { silence is the last thing you will ever hear from me. } \\
\text { pic.twitter.com/hLmBJ7PgmK }\end{array}$ \\
\hline 17 & benshapiro & 12,843 & $\begin{array}{c}\text { News } \\
\text { personality }\end{array}$ & $\begin{array}{l}\text { Just reported @Rosie for targeted harassment, mainly } \\
\text { to see if Twitter does indeed have a double standard. } \\
\text { Everyone knows if Rosie were conservative, Twitter } \\
\text { would suspend her in a hot second. So, Twitter, put } \\
\text { your money where your mouth is. \#MeToo }\end{array}$ \\
\hline 18 & nowthisnews & 12,808 & News outlet & $\begin{array}{l}\text { Life coach Tony Robbins says women are using } \\
\text { \#MeToo to make themselves 'significant' — but this } \\
\text { brave sexual abuse survivor called him out } \\
\text { pic.twitter.com/wYxhlmc10u }\end{array}$ \\
\hline 19 & meliegodart & 12,173 & Individual & $\begin{array}{l}\text { Quandtulis les tweets sur \#balancetonporc ... tute rend } \\
\text { compte que... pic.twitter.com/On7HkGWTjz }\end{array}$ \\
\hline 20 & funder & 11,675 & $\begin{array}{l}\text { News } \\
\text { personality }\end{array}$ & $\begin{array}{l}\text { Over } 100 \text { members of Congress (and counting) are } \\
\text { now demanding an investigation into the } 19 \text { sexual } \\
\text { assault allegations against Trump. RT if you agree } \\
\text { Trump's sex crimes should be investigated } \\
\text { immediately. \#TrumpSexProbe \#MeToo }\end{array}$ \\
\hline
\end{tabular}

The role of journalists is more prominent in these highly retweeted tweets as six out of 20 are posted by news personalities. It is noticeable that, although users categorized as political do not appear (except for @womensmarch), seven out of 20 tweets are explicitly political in their content. Democratic writer and podcaster Scott Dworkin (@funder) is the author of three of the most retweeted tweets, which all constitute a direct attack on Trump. Similarly, right-wing commentator Ben Shapiro (@benshapiro) draws attention to a perceived double standard in silencing conservative users. Two more tweets (from @LeeannTweeden and @Alyssa_Milano) address the accusations of sexual assault against Democratic Senator Al Franken. Finally, two tweets (from @womensmarch and @cnnbrk) are related to the Women's March that took place in Los Angeles. Other categories of users include female celebrities, either disclosing their own \#MeToo stories or commenting on the \#MeToo movement. Unlike the most mentioned users, authors of top retweeted posts also include several Twitter influencers and common users. It is interesting to note that there is little overlap between the list of most mentioned users (Table 1) and the authors of top retweeted posts. As previously suggested, mentioned users are the subject of the conversation but do not contribute actively, while the most retweeted users are influential in spreading their messages, but do not personally become central to the conversation. The final dimension analyzed is the role of hashtags. In addition to the hashtags that were used as criteria to select tweets for the construction of the dataset, Table 3 also shows the hashtags that users 
most often employed to discuss a variety of salient topics throughout the conversation. The hashtags that were used to collect the dataset inevitably appear most consistently; \#MeToo is largely the most used hashtag, in addition to \#balancetonporc, \#120db, and \#quellavoltache. Hashtags also offer commentary on real-time events; in the sample, these include two political demonstrations in the US: \#marchforourlives (a demonstration against gun violence held in March 2018 in Washington, D.C.), and \#womensmarch2018/\#womensmarch (2018 edition of the Women's March).

Correspondingly, many hashtags focus on national politics. The majority refer to US politics, showing again a polarized approach especially around the figure of Donald Trump in connection with \#MeToo. US political hashtags include \#maga (short for "Make America Great Again", a slogan used by Trump supporters), \#trump, \#resist, and \#theresistance (hashtags used by anti-Trump protesters). A smaller percent of hashtags focus on other national contexts, namely \#abusefreeindia and \#svpol (Swedish politics).

Other types of hashtags include \#TimesUp, often used in conjunction with \#MeToo. Many hashtags comment on television programming or show business events, such as \#am2dm, \#goldenglobes, \#oscars, \#grammys, and \#oprah. Finally, many hashtags discuss some of the most prominent men accused of sexual violence and harassment.

Table 3: Most Used Hashtags in the Dataset (Source: Authors' depiction)

\begin{tabular}{|r|l|l|}
\hline & Hashtag & $\%$ \\
\hline 1 & \#metoo & 72.6 \\
\hline 2 & \#balancetonporc & 4.1 \\
\hline 3 & \#120db & 1 \\
\hline 4 & \#timesup & 0.8 \\
\hline 5 & \#am2dm & 0.5 \\
\hline 6 & \#quellavoltache & 0.3 \\
\hline 7 & \#goldenglobes & 0.2 \\
\hline 8 & \#oscars & 0.2 \\
\hline 9 & \#abusefreeindia & 0.2 \\
\hline 10 & \#maga & 0.1 \\
\hline 11 & \#marchforourlives & 0.1 \\
\hline 12 & \#resist & 0.1 \\
\hline 13 & \#trump & 0.1 \\
\hline 14 & \#sexualharassment & 0.1 \\
\hline 15 & \#hollywood & 0.1 \\
\hline 16 & \#weinstein & 0.1 \\
\hline
\end{tabular}




\begin{tabular}{|l|l|l|}
\hline 17 & \#women & 0.1 \\
\hline 18 & \#harveyweinstein & 0.1 \\
\hline 19 & \#womensmarch2018 & 0.1 \\
\hline 20 & \#theresistance & 0.1 \\
\hline 21 & \#grammys & 0.1 \\
\hline 22 & \#oprah & 0.1 \\
\hline 23 & \#feminism & 0.1 \\
\hline 24 & \#womensmarch & 0.1 \\
\hline 25 & \#svpol & 0.1 \\
\hline 26 & \#resistance & 0.1 \\
\hline 27 & \#sexualassault & 0.1 \\
\hline 28 & \#billcosby & 0.1 \\
\hline 29 & \#azizansari & 0.1 \\
\hline 30 & \#internationalwomensday & 0.1 \\
\hline
\end{tabular}

\section{CONCLUSION}

The presence of US politics appears consistently across all dimensions of the \#MeToo conversation. The top mentioned users (Table 1) and top retweeted posts (Table 2) - which represent the users and posts that received the most attention - show the centrality of US political figures and organizations in the debate, with partisan hostility at times overshadowing the initial \#MeToo objective of combating sexual violence. This prevalence of US-centric politics in the conversation risks weakening the transnational nature of the movement since the unequal distribution of online attention hinders the global commonality of women's experiences of violence.

These metrics confirm the initial hypothesis that \#MeToo has become a polarizing issue in US partisan politics and that it was often weaponized by rival political factions. As previously introduced, protests against President Trump provided fertile ground for the escalation of \#MeToo, and indeed he appears to be a central figure in the discussion, with $4.4 \%$ of all tweets in the dataset mentioning him. ${ }^{6}$ This mirrors the findings from studies that explored a later period of activity - the Kavanaugh controversy in 2018 (Boyle and Rathnayake 2019; Pollino 2020). Consequently, it can be said that the \#MeToo conversation reflects the "highly polarized political climate in the USA" (Boyle and Rathnayake 2019, 1). Siding 'with' or 'against' \#MeToo quickly became the source of division in the same manner as other social issues that characterize American "culture wars" (Hunter 1991), such as abortion, LGBTQ + rights, and climate

\footnotetext{
${ }^{6}$ This figure includes mentions for @ 'Trump' in the posts.
} 
change. Opinions on these matters often run alongside conservative/liberal denominations, and they are so steeped in competing for moral visions that opposite views are often irreconcilable. These controversial issues, then, generate "political and social hostility rooted in different systems of moral understanding" in the American public debate (Hunter 1991, 42).

As a result, issues that are social become shorthand for political affiliation. In this sense, it is arguable that \#MeToo was in many instances used for political ends that were partially removed from the original intent of combating sexual violence. For example, three out of the top 20 retweeted posts are by Democratic writer and podcaster Scott Dworkin (@funder), and they all call for an investigation into the sexual assault allegations against Donald Trump. In this instance, liberals are using the increased intolerance for sexual misconduct and capitalizing on the \#MeToo momentum to mobilize against the president. A more complex picture of the implications of \#MeToo for oppositional party politics emerges in this tweet by Alyssa Milano from Table 2, which received 15,462 retweets:

At the very same time that we are asking Franken to resign from the senate -- we are allowing an accused child molester to run for senate.

At the very same time that 'Silence Breakers' is the \#TimePersonOfTheYear -- a self-professed pussy grabber was runner-up.

\#MeToo (@Alyssa_Milano Dec 6, 2017)

In the first half of the tweet, Milano expresses her support for the calls for Democratic Senator Al Franken to resign following allegations of sexual improprieties. At the same time, she points to the contradiction of another accused sexual predator running for Senate, Republican Roy Moore, who had received Trump's endorsement two days before this tweet. In the second half of the tweet, another parallel is drawn between the cultural impact of \#MeToo - exemplified by the Time magazine cover and, again, the unsuitability of having an accused sexual predator as president. This position well encapsulates the tension of the co-existence of "popular feminism" and "popular misogyny" described by Banet-Weiser (2018).

The present dataset only covers the \#MeToo conversation until April 2018; as previously mentioned, this political polarization was further exacerbated in SeptemberOctober 2018, when Judge Brett Kavanaugh was nominated and then confirmed as a Supreme Court Justice despite accusations of sexual assault. In their analysis of the Kavanaugh controversy on Twitter, Dejmanee et al. $(2020,3956)$ confirm "Banet-Weiser's (2018) notion that popular feminism and popular misogyny are structurally linked and emerge through the same cultural and technical mechanisms, particularly about the attention economy and social media platforms".

The same polarization of attitudes was also present in Donald Trump's own words on the Kavanaugh controversy, as he declared that "It's a very scary time for 
young men in America when you can be guilty of something you might not be guilty of" (Hutzler 2018). When asked he had a message for young women, he responded by stating that "women are doing great".

The conversation around \#MeToo can therefore be conceptualized as "culture war discourse" since it aims to be "rhetorical and polemical, designed to dramatize perceptions of conflict and division for political gain" (Davis 2019, 4). As demonstrated by the results of this study, such discourse has permeated the \#MeToo conversation since its beginning, reflecting the increasing polarizing tendencies in the US political debate. 


\section{ACKNOWLEDGMENTS}

I would like to thank Prof. Marcella Corsi and Prof. Giulia Zacchia of Minerva Lab at Sapienza University of Rome for providing the dataset for this research. 


\section{REFERENCES}

1. Anderson, Monica, and Toor, Skye. 2018. How social media users have discussed sexual harassment since \#MeToo went viral. Pew Research Center.

2. Banet-Weiser, Sarah. 2018. Empowered: Popular feminism and popular misogyny. Durham: Duke University Press.

3. Banet-Weiser, Sarah, Gill, Rosalind, and Rottenberg, Catherine. 2020. "Postfeminism, popular feminism and neoliberal feminism? Sarah Banet-Weiser, Rosalind Gill and Catherine Rottenberg in conversation". Feminist Theory, 21(1): 3-24.

4. Boyle, Karen. 2019. \#MeToo, Weinstein and Feminism. Cham: Palgrave Pivot.

5. Boyle, Karen, and Rathnayake, Chamil. 2020. "\#HimToo and the networking of misogyny in the age of \#MeToo". Feminist Media Studies, 20(8): 1259-1277.

6. Bruns, Axel. 2018. "Big Social Data Approaches in Internet Studies: The Case of Twitter". In J. Hunsinger, L. Klastrup and M. Allen (Eds.) Second International Handbook of Internet Research, edited by Jeremy Hunsinger, Matthew M. Allen, Lisbeth Klastrup, 65-81. Dordrecht: Springer.

7. Bruns, Axel, and Stieglitz, Stefan. 2012. "Quantitative approaches to comparing communication patterns on Twitter". Journal of Technology in Human Services, 30(3-4): 160-185.

8. Bruns, Axel, and Stieglitz, Stefan. 2013. "Towards more systematic Twitter analysis: metrics for tweeting activities". International Journal of Social Research Methodology, 16(2): 91-108.

9. Bruns, Axel, and Stieglitz, Stefan. 2014. "Twitter data: What do they represent?". It - Information Technology, 56(5).

10. Bruns, Axel, Brenda Moon, Avijit Paul, and Felix Münch. 2016. "Towards a typology of hashtag publics: a large-scale comparative study of user engagement across trending topics". Communication Research and Practice, 2(1): 20-46.

11. Clark-Parsons, Rosemary. 2019. "'I SEE YOU, I BELIEVE YOU, I STAND WITH YOU': \#MeToo and the performance of networked feminist visibility". Feminist Media Studies, 21(3): 362-380.

12. Davis, Mark. 2019. "A new, online culture war? The communication world of Breitbart. com." Communication Research and Practice, 5(3): 241-254.

13. De Benedictis, Sara, Shani Orgad, and Catherine Rottenberg. 2019. "\#MeToo, popular feminism and the news: A content analysis of UK newspaper coverage". European Journal of Cultural Studies, 22(5-6): 718-738.

14. Dejmanee, Tisha, Zulfia Zaher, R. Samantha, and Michael J. Papa. 2020. "\#MeToo; \#HimToo: Popular Feminism and Hashtag Activism in the Kavanaugh Hearings". International Journal of Communication, 14: 3946-3963. 
15. Fahrenthold, David A. 2016. "Trump recorded having an extremely lewd conversation about women in 2005". The Washington Post. https://www.washingtonpost.com/politics/trump-recorded-having-extremelylewd-conversation-about-women-in-2005/2016/10/07/3b9ce776-8cb4-11e6bf8a-3d26847eeed4_story.html

16. Fileborn, Bianca, and Loney-Howes, Rachel. (Eds.). 2019. \#MeToo and the Politics of Social Change. Cham: Palgrave Macmillan.

17. Fisher, Dana R., Dawn M. Dow, and Rashawn Ray. 2017. "Intersectionality takes it to the streets: Mobilizing across diverse interests for the Women's March". Science Advances, 3(9): 1-8.

18. Hunter, James Davison. 1991. Culture Wars: The Struggle to Define America. New York: Basic.

19. Hutzler, Alexandra. (2018, October 2). "Donald Trump: It's a very "Scary" Time for Young Men in America, but Women Are "Doing Great." Newsweek. https://www.newsweek.com/donald-trump-scary-time-young-men-america1149502

20. Kantor, Jodi, and Twohey, Megan. (2017, October 5). "Harvey Weinstein paid off sexual harassment accusers for decades". New York Times. https://www.nytimes.com/2017/10/05/us/harvey-weinstein-harassmentallegations.html

21. Lam, Onyi, Hughes, Adam, \& van Kessel, Patrick. (2018, February 1). "There's a large gender gap in congressional Facebook posts about sexual misconduct". Pew Research Center. https://www.pewresearch.org/fact-tank/2018/02/01/theresa-large-gender-gap-in-congressional-facebook-posts-about-sexual-misconduct/

22. Löffler, Marion, Russell Luyt, and Kathleen Starck. 2020. "Political masculinities and populism". NORMA, 15(1): 1-9.

23. Maas, Megan K., Heather L. McCauley, Amy E. Bonomi, and S. Gisela Leija. "I was grabbed by my pussy and its \#NotOkay": A Twitter backlash against Donald Trump's degrading commentary." Violence Against Women, 24(14): 1739-1750.

24. Papacharissi, Zizi, and de Fatima Oliveira, Maria. 2012. "Affective news and networked publics: The rhythms of news storytelling on \#Egypt". Journal of Communication,62(2): 266-282.

25. Poell, Thomas, and Van Dijck, José. 2016. "Constructing public space: Global perspectives on social media and popular contestation". International Journal of Communication, 10(9): 226-234.

26. Pollino, Madison A. 2020. "(Mis)Representations of sexual violence: the Brett Kavanaugh and Christine Blasey Ford testimonies". Critical Studies in Media Communication, 37(1): 71-84.

27. Rhodes, Jesse H., Elizabeth A. Sharrow, Jill S. Greenlee, and Tatishe M. Nteta. 2020. "Just Locker Room Talk? Explicit Sexism and the Impact of the Access 
Hollywood Tape on Electoral Support for Donald Trump in 2016". Political Communication, 37(6): 741-767.

28. Rosewarne, Lauren. 2019. "\#MeToo and the reasons to be cautious". In \#MeToo and the Politics of Social Change, edited by Bianca Fileborn, and Rachel LoneyHowes, 171-184. Cham: Palgrave Macmillan.

29. Rottenberg, Catherine. 2019. "\#MeToo and the prospects of political change". Soundings, 71(71): 40-49.

30. Sayej, Nadja. (2017, December 1). "Alyssa Milano on the \#MeToo movement: "We're not going to stand for it anymore". The Guardian. https://www.theguardian.com/culture/2017/dec/01/alyssa-milano-mee-toosexual-harassment-abuse

31. Siddiqui, Sabrina (2019, December 15). "Kirsten Gillibrand: can the \#MeToo senator become Madam President?" The Guardian. https://www.theguardian.com/us-news/2019/jan/17/kirsten-gillibrandformidable-2020-presidential-candidate

32. Zacchia, Giulia, Corsi, Marcella, and Botti, Fabrizio. 2019. "The complexity of \#MeToo: the evolution of a Twitter campaign in Europe". In The \#MeToo Social Media Effect and its Potentials for Social Change in Europe, edited by Marcella Corsi, Laeticia Thissen, and Giulia Zacchia, 12-37. Brussels: Foundation for European Progressive Studies. 